\title{
Role of MAP Kinase Signaling in Secondary Metabolism and Adaptation to Abiotic/Fungicide Stress in Fusarium
}

\author{
Emese D. Nagygyörgy, László Hornok and Attila L. Ádám \\ Agricultural Biotechnology Center and Department of Plant Protection, \\ Szent István University, Mycology Group of the Hungarian Academy of Sciences, Gödöllö, \\ Hungary
}

\section{Introduction}

Phosphorylation by protein kinases including mitogen activated protein kinases (MAPKs) is a major signal transduction mechanism used by eukaryotic cells to regulate different functions, virtually almost all activities that define their phenotypic behavior. Considering their diverse cellular roles, it was not surprising to find that significant portions of eukaryotic genes are devoted to code for protein kinases. For example, the genome of Saccharomyces cerevisiae, the budding yeast contains 130 distinct protein kinase encoding genes, representing approximately $2 \%$ of the entire yeast genome (Hunter and Plowman, 1997). The human genome contains 518 protein kinase genes comprising $1.7 \%$ of the genome (Manning et al., 2002).

The MAPK signal transduction pathways constitute a cascade of phosphorylation events that transmit extracellular signals from membrane-bound receptors to the nucleus. MAPKs are highly selective for phosphorylation of serine/threonine residues lying immediately Nterminal to a proline residue within a peptide substrate (Hanks and Hunter, 1995; Brábek and Hanks, 2004). MAP kinase cascades control almost all aspects of fungal growth, development, sexual and asexual reproduction, metabolism, proliferation and stress tolerance.

Two of the three MAP kinase pathways of filamentous fungi, the HOG1 (high osmolarity glycerol according to yeast nomenclature) MAPK and the CWI (cell wall integrity) MAPK (homologous to Slt2/Mpk1 in yeast) pathways take part in abiotic stress tolerance including tolerance to salt, osmotic, oxidative, heat, cold, arsenite and citric acid stressors. Recently the HOG MAPK pathway has also been indicated in tunicamycin induced endoplasmic reticulum stress in S. cerevisiae (Torres-Quiroz et al., 2010). The third MAPK route, the socalled pathogenicity MAP kinase (PMK) pathway is homologous to the mating/ filamentation Fus3/Kss1 MAPK pathway of the yeast. PMK is required for the infection process including penetration into the host cells and invasive growth. This pathway is also involved in the yeast-to-hyphal transition in dimorphic species. As far as studies on Fusarium species are concerned, the Fmk1 and the Gpmk1 MAP kinases of Fusarium oxysporum (Di Pietro et al., 2001) and Fusarium graminearum (Jenczmionka et al., 2003), 
respectively were also found to be essential for pathogenicity. These PMK-type MAP kinases regulates the expression of several genes encoding cell-wall degrading hydrolytic enzymes (Jenczmionka and Schäfer, 2005).

Although PMK-type MAP kinases were generally regarded to have not much role in stress adaptation, recent studies demonstrated that the pathogenicity MAPK pathway controls the oxidative stress response in Cochliobolus heterostrophus (Izumitsu et al., 2009). These observations highlight a more complex nature of stress signaling in filamentous fungi as it was anticipated previously (Aguirre et al., 2006).

We present here a functional analysis of $\Delta F v h o g 1$ and $\Delta F v m k 2$ CWI MAPK mutants of $F$. verticillioides by comparing their sensitivity to different oxidative stressors. Fusarium verticillioides (teleomorph: Gibberella moniliformis) is a world-wide occurring pathogen of maize that synthesizes a range of secondary metabolites, including fumonisins and carotenoids. To the best of our knowledge this is the first report on the comparison of oxidative stress tolerance of different MAPK mutants of the same filamentous fungus species. We also found that both $\triangle F v h o g 1$ and $\triangle F v m k 2$ CWI MAPK gene-disruption mutants of $F$. verticillioides resulted in increased sensitivity to methylglyoxal, a toxic glycolytic byproduct suggesting a double MAPK regulation of the cellular response to this compound. Secondary metabolite production is also regulated by different MAPK pathways in fungi: we provide here additional information on the recent findings available for fusaria. As the highly conserved fungicide signaling by fludioxonil is not dependent on the histidine kinase-HOG1 MAPK route in all filamentous fungi (Liu et al., 2008) we compared the fludioxonil and hydrogen peroxide sensitivity of three Fusarium species. The extreme sensitivity of F. graminearum to fludioxonil and hydrogen peroxide was not associated with substantial changes in HOG MAPK mediated osmotic stress tolerance. We also found that $\Delta$ hog1 mutants of two other Fusarium species showed fludioxonil tolerant and hydrogenperoxide sensitive phenotypes, similarly to other filamentous species.

\section{The role of HOG1 MAPK signaling in stress and fungicide tolerance of Fusarium species}

Orthologues of the yeast HOG1 pathway genes have been identified either by functional or in silico analysis in several Fusarium species, including F. graminearum, Fusarium proliferatum, F. oxysporum, and F. verticillioides (Di Pietro et al., 2001; Ochiai et al., 2007; Ádám et al., 2008a, b; Rispail et al., 2009; Rispail and Di Pietro, 2010). In F. proliferatum, the HOG1 MAPK pathway plays a pivotal role in stress tolerance: this route takes part in salt, osmotic, heat, UV and oxidative (hydrogen peroxide) stress responses, but it is not required for invasive growth, sexual and asexual sporulation (Ádám et al., 2008a, b). Osmotic stress caused a considerably higher rate of cell death in the $\triangle F p h o g 1$ MAPK gene disruption mutants as compared to the wild type strain. More importantly, when the fungi were subjected to osmotic $(4 \% \mathrm{NaCl})$ stress, levels of reactive oxygen species (ROS), mitochondrial membrane permeability transition, nuclear disintegration and DNA fragmentation, four independent markers of programmed cell death (PCD) all showed significant increases in the $\Delta F$ phog1 mutants in comparison to the wild type strain suggesting that an important role of the functional Hog1 MAPK gene is attenuating apoptotic phenotypes under stress conditions (Ádám et al., 2008a). Fig. 1. shows intense cell death symptoms and accumulation of ROS indicated by blue stained morphologically abnormal cells and green fluorescent cells (indicated by arrow), respectively in a $\Delta F p h o g 1$ gene-disruption mutant subjected to salt stress after adding $4 \%$ 
$(\mathrm{w} / \mathrm{v}) \mathrm{NaCl}$ to the culture medium. Similarly to $\Delta$ hog1 mutants of other fungi, like Neurospora crassa, Aspergillus nidulans, C. heterostrophus and Colletotrichum lagenarium the $\triangle F$ phog1 MAPK mutants of $F$. proliferatum became tolerant to phenylpyrrole and dicarboximide fungicides (Zhang et al., 2002; Noguchi et al., 2004; Yoshimi et al., 2005; Ádám et al., 2008b; Hagiwara et al., 2009). Although the exact mode of action of these compounds is still unclear, the finding that heterologous expression of Hik1, the histidine kinase (HK) gene of Magnaporthe oryzae in the yeast, $S$. cerevisiae that contain only one HK gene, $\operatorname{Sln} 1$ confers susceptibility in this otherwise fludioxonil-resistant organism, suggests that class III HKs, located upstream of the HOG1 MAPK cascade are possible targets of this fungicide (Motoyama et al., 2005). The class III HKs responsible for elevated osmo-tolerance and increased fludioxonil sensitivity in filamentous fungi are not the orthologues of Sln1 of the yeast (Catlett et al., 2003). Inactivation of Fhk1, a class III HK in F. oxysporum resulted in osmo-sensitivity and resistance to phenylpyrrole and dicarboximide fungicides (Rispail and Di Pietro, 2010). The increased tolerance of the $\Delta F$ phog1 mutants of F. proliferatum to fludioxonil and vinclozoline (Ádám et al., 2008b) suggests that functional HK-HOG1 MAPK pathway is required for sensitive response to these fungicides in Fusarium species. In silico analysis of HKs by reciprocal BLASTP searches in Fusarium genome sequences led to the identification of Fhk1 (FOXG_01684) orthologues both in F. verticillioides (hypothetical protein FVEG_08048) and F. graminearum (hypothetical protein FGSG_07118) (Nagygyörgy and Ádám, unpublished).



Fig. 1. Double staining of Fusarium proliferatum $\triangle$ Fphog1-24 gene-disruption MAP kinase mutant with 2,7-dichlorodihydrofluorescein diacetate (DCHFDA) and Evans blue after $\mathrm{NaCl}(4 \% \mathrm{w} / \mathrm{v})$ exposition. Intensive green fluorescence (indicated by arrow) and dark blue discoloration of the cells indicate accumulation of reactive oxygen species (ROS) and cell death, respectively. 
HKs have five HAMP (histidine kinase, adenylate cyclase, methyl binding protein and phosphatase) repeats: mutations in these sequences are responsible for the increased osmosensitivity and fungicide resistance of N. crassa, C. heterostrophus, Alternaria brassicicola and Botrytis cinerea (Ochiai et al., 2001; Yoshimi et al., 2004; Motoyama et al., 2005; Viaud et al., 2006). Recent microarray analyses have further shown that the transcriptional response to fludioxonil depends on a Hog1 orthologue in A. nidulans. This response overlaps, in part with the transcriptional response to hyperosmotic stress but depends on factors other than the AtfA transcription factor responsible for conidial stress tolerance (Hagiwara et al., 2009). Thus the identification of transcription factor(s), that are located downstream of Hog1 MAPK and influence gene expression response to fludioxonil requires further studies.

Although fungicide signaling by fludioxonil is highly conserved in filamentous fungi, response to this compound is still not entirely dependent on the HK-HOG1 MAPK route in all species. For example, the $\Delta s a k 1$ (Hog1 orthologue) knockout mutants of $B$. cinerea maintained their sensitive phenotype to fludioxionil (Liu et al., 2008) indicating the complex nature of this signaling pathway. On-going research of our laboratory on fludioxonil sensitivity of three Fusarium species with available genome sequences (F. graminearum PH-1/NRRL 31084, F. oxysporum 4287 and F. verticillioides FGSC 7600; http: //www.broadinstitute. org/annotation/genome/Fusariumgroup/MultiHome.html) led to somewhat surprising results (Fig. 2).

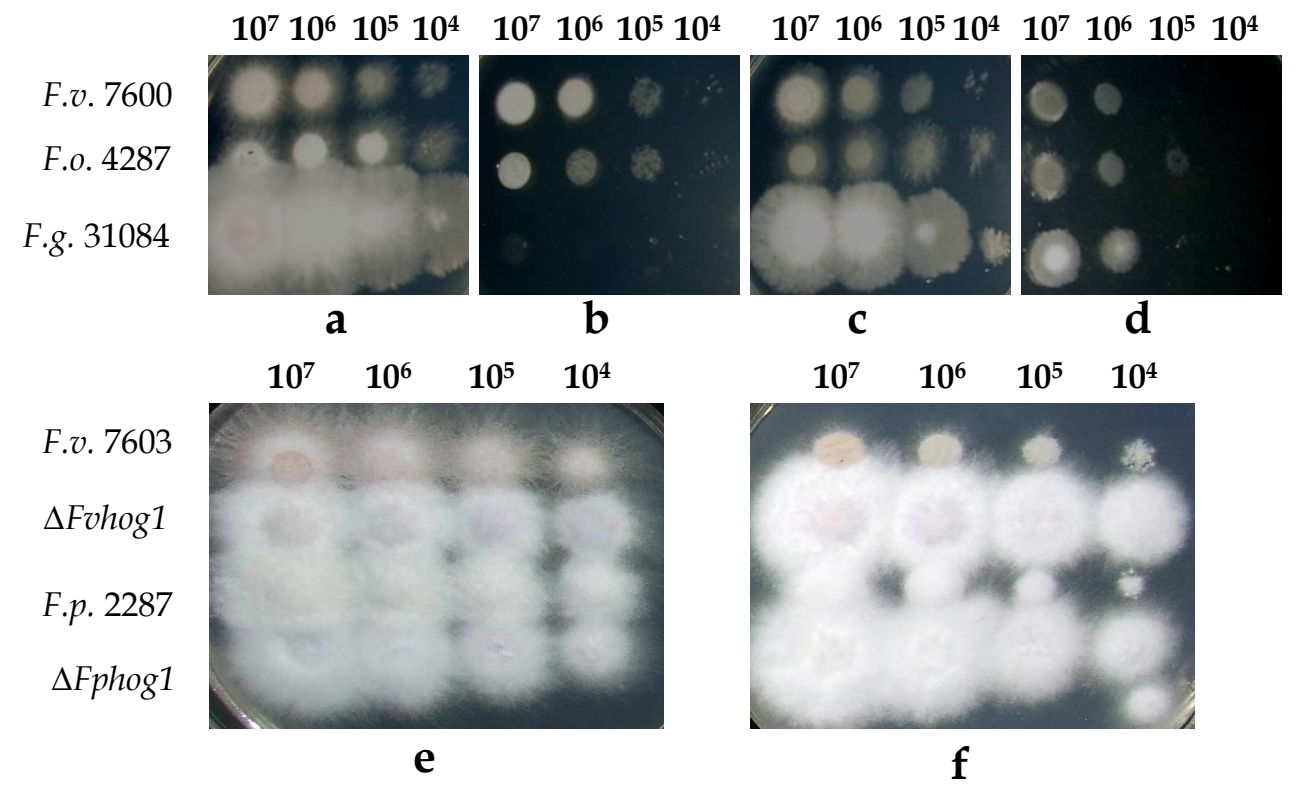

Fig. 2. Growth sensitivity of three Fusarium species: Fusarium oxysporum 4287, Fusarium verticillioides FGSC 7600 and Fusarium graminearum PH-1/NRRL 31084 against different stressors (a-d) and sensitivity of $\Delta$ hog1 mutants of F. verticillioides FGSC 7603 and F. proliferatum FGSC 2287 ( $\Delta$ Fvhog1-14 and $\Delta$ Fphog1-24, respectively) against fludioxonil (e-f). Five-five $\mu 1$ of indicated concentrations of conidia (cells $/ \mathrm{ml}$ ) was spotted on $(\mathrm{a}, \mathrm{e})$ complex medium $(\mathrm{CM})$ agar plates and CM agar plates supplemented with (b, f) $10 \mu \mathrm{g} / \mathrm{ml}$ fludioxonil, (c) $4 \%$ (w/v) $\mathrm{NaCl}$ and (d) $2 \mathrm{M}$ sorbitol. Incubation time was 3 days for all plates at $24{ }^{\circ} \mathrm{C}$. 
F. graminearum showed increased sensitivity to this fungicide as compared to the other two species (Fig. 2a and b), but fludioxonil sensitivity was not accompanied with substantial changes in osmo-sensitivity of this fungus (Fig. 2c and d). On the other hand, $\Delta$ hog1 mutants of F. proliferatum and F. verticillioides showed fludioxonil tolerance (Fig. $2 \mathrm{e}$ and $\mathrm{f}$ ), paralleled with elevated osmo-sensitivity. Although these results do not exclude the involvement of the HKHOG1 MAPK pathway in these phenotypes, further studies are needed to a better understanding of fungicide stress responses in Fusarium species.

\section{The role of MAPK pathways in secondary metabolism of Fusarium species}

In addition to its role in stress and fungicide tolerance, the HOG1 MAPK pathway plays also an important role in the regulation of secondary metabolism in different Fusarium species (Ochiai et al., 2007; Kohut et al., 2009). Disruption of either Fgos2 (a HOG-type MAPK orthologue) or Fgos4 (encoding a MAPK kinase) or Fgos5 (encoding a MAPK kinase kinase) blocked trichotecene production in F. graminearum and substantially reduced expression of the trichotecene gene cluster. On the other hand, amounts of aurofusarin were increased in all three types of mutants (Ochiai et al., 2007). Deoxynivalenol production is controlled by Mgv1 CWI MAPK in F. graminearum (Hou et al., 2002). Nitrogen depletion induced the production of fumonisin B1, a polyketide derivative mycotoxin and increased the expression of fuminisin biosynthesis genes in F. proliferatum. Under nitrogen starvation (absence of any $\mathrm{N}$-source) conditions deletion of Fphog1, a HOG-type MAP kinase gene resulted in further increases in FUM1 and FUM8 gene expression, as well as fumonisin B1 production suggesting that this response is mediated via the HOG-type MAPK pathway in $F$. proliferatum (Kohut et al., 2009). In a more recent study Fvmk1, a PMK-type MAPK gene was identified as a positive regulator of fumonisin B1 production in F. verticillioides (Zhang et al., 2011). On the contrary, fumonisin B1 production was not regulated by cAMP signaling either in F. proliferatum (Kohut et al., 2010) or F. verticillioides (Choi and $\mathrm{Xu}, 2010$ ). This signaling route regulates, however negatively regulates the production of bikaverin, another polyketide metabolite in Fusarium species (Kohut et al., 2010; Choi and Xu, 2010; GarcíaMartínez et al., 2011). Moreover, the production of another secondary metabolite such as carotenoids is upregulated in Fusarium species not only by cAMP signaling (GarcíaMartínez et al., 2011) but other regulatory elements related to sexual reproduction (Ádám et al., 2011).

\section{Complexity of oxidative stress signaling in fungi: Role of the HOG1 and the CWI MAPK pathways}

Previous research with different species indicated that, besides the HOG MAPK pathway (Aguirre et al., 2006; Du et al., 2006; Ádám et al., 2008a), the CWI MAPK pathway (Krasley et al., 2006; Valiante et al., 2007) also has a role in oxidative stress tolerance of fungi. To compare the particularities of the two pathways we generated both $\Delta h \circ g 1$ ( $\triangle$ Fvhog1) and CWI MAPK ( $\triangle$ Fvmk2) gene-disruption mutants in a single fungus species, $F$. verticillioides as we have described earlier (Ádám et al., 2008a). These mutants were tested for oxidative stress tolerance in conidial dilution assay using hydrogen peroxide, menadione, diamide and methylglyoxal as stressors. Although all of these compounds elicit finally oxidative stress, the mechanisms they do this are different. Hydrogen peroxide induces lipid peroxidation, protein and DNA damage directly or indirectly and contributes to the formation of hydroxyl radicals (OH.) via 
the Fenton reaction (Thön et al., 2007). Menadione is a redox cycling reagent that acts by generating superoxide radicals $\left(\mathrm{O}_{2-}^{-}\right)$using $\mathrm{NADPH}$ as a cofactor. Diamide causes depletion of the reduced glutathione pool and perturbation of the redox balance of cells; this compound also reacts with sulfhydryl groups of proteins in a reversible way (Pócsi et al., 2005; Thön et al., 2007). Methylglyoxal is a highly toxic natural glycolytic by-product interacting with proteins in a reversible way and, at higher concentrations $(8-10 \mathrm{mM})$ it can deplete the glutathione pool in yeast cells (Aguilera et al., 2005).

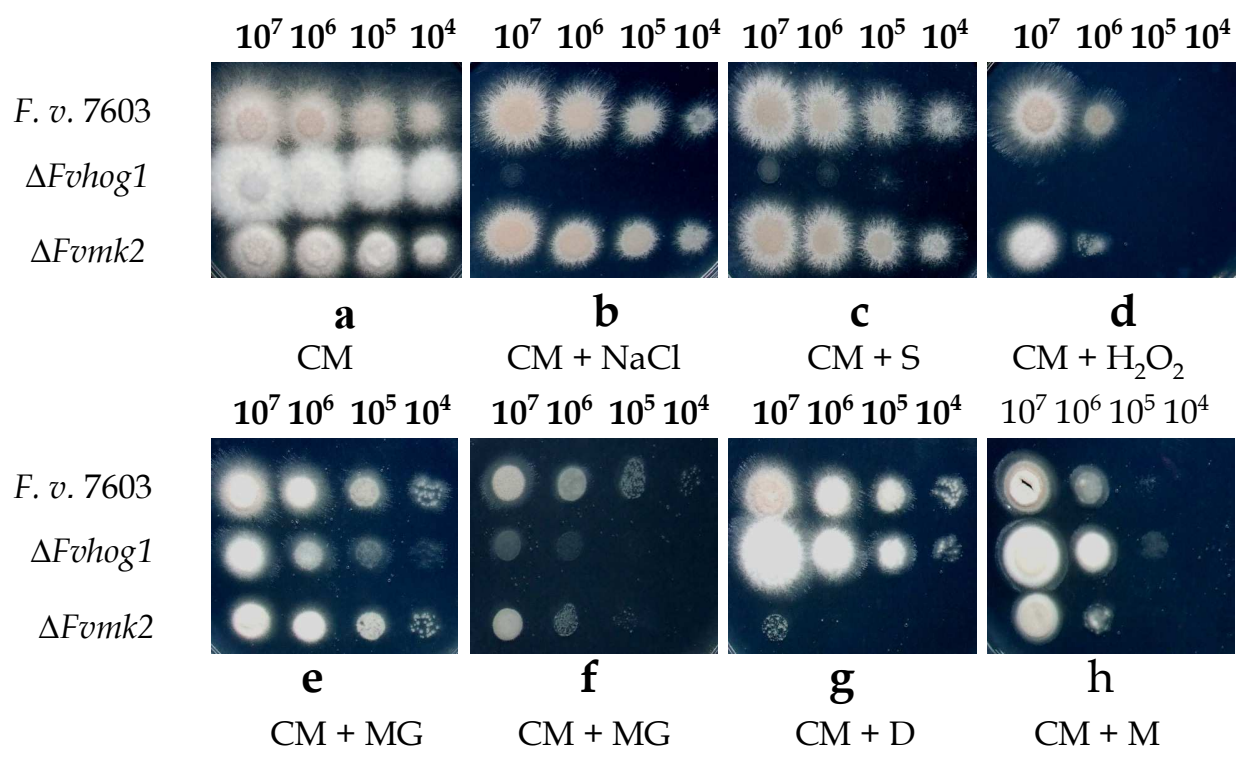

Fig. 3. Differential sensitivity of $\Delta$ Fvhog1-14 and $\Delta F v m k 2-16$ CWI MAPK mutants of Fusarium verticillioides FGSC 7603 against oxidative stressors. Five-five $\mu 1$ of indicated concentrations of conidia (cells/ml) was spotted on (a) complex medium (CM) agar plate and CM agar plates supplemented with (b) $4 \%$ (w/v) NaCl, (c) $2 \mathrm{M}$ sorbitol (S), (d) $2 \mathrm{mM}$ hydrogen peroxide $\left(\mathrm{H}_{2} \mathrm{O}_{2}\right)$, (e) $5 \mathrm{mM}$ methylglyoxal (MG), (f) $10 \mathrm{mM}$ methylglyoxal (MG), (g) 0,5 mM diamide (D) and (h) $0,03 \mathrm{mM}$ menadione (M). Incubation time was 3 days for all plates at $24{ }^{\circ} \mathrm{C}$.

The $\Delta$ Fvhog1 mutant of $F$. verticillioides was highly sensitive to the osmotic stressors, sodium chloride and sorbitol (Fig 3a, b and c), similar to our former results with F. proliferatum $\Delta$ hog 1 mutants (Ádám et al., 2008a). On the contrary, the $\Delta F v m k 2$ mutant showed no elevated osmo-sensitivity (Fig 3a, b and c). The $\Delta$ Fohog1 mutant was sensitive not only to osmotic stressors but, as well as to hydrogen peroxide and methylglyoxal. However, this mutation caused no change in menadione and diamide sensitivity (Fig. 3a, d, e, f g and h). This is a first report on the involvement of HOG MAPK pathway in methylglyoxal tolerance of a filamentous species. Formerly Aguilera et al. (2005) reported on methylglyoxal sensitivity of $\Delta$ hog1 mutants of $S$. cerevisiae. $\Delta H o g 1$ mutants of filamentous species showed different oxidative stress sensitivity. Mutants of $A$. fumigatus lacking the MAP kinase $\Delta s a k A / \Delta h o g 1$ were more sensitive to $\mathrm{H}_{2} \mathrm{O}_{2}$ and menadione compared to wild type strain (Du et al., 2006). 
In F. oxysporum the Fhk1 HK mutant, deficient in an upstream element of the HOG1 MAPK pathway is sensitive to menadione induced oxidative stress but not to $\mathrm{H}_{2} \mathrm{O}_{2}$ (Rispail and Di Pietro, 2010).

Results obtained with the $\triangle F v m k 2$ CWI MAPK mutants were completely different: they showed no elevated osmo-sensitivity, but their sensitivity to methylglyoxal and diamide increased as compared to the wild type strain (Figs. 3a, b, c, d, e, f, g and h). According to these results, the cellular response to methylglyoxal is regulated by both the HOG1 and CWI MAPK pathway, but the other stressors are signaled separately either by the HOG1 or CWI MAPK pathway. As both methylglyoxal and diamide interact mainly with glutathione metabolism, the possible role of CWI MAPK is to maintain glutathione pools under stress conditions. As regarding the oxidative stress sensitivity of other species, CWI MAPKs played a fluctuating but positive regulatory role in stress tolerance. An exceptional case is $A$. fumigatus: the deletion of MpkA CWI MAPK gene resulted in increased $\mathrm{H}_{2} \mathrm{O}_{2}$ tolerance and sensitivity to menadione and diamide (Valiante et al., 2007). In the case of S. cerevisiae

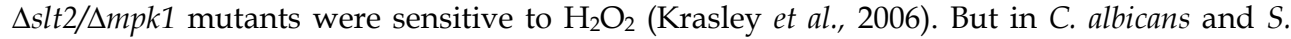
pombe, deletion mutants of $\Delta m k c 1$ and $\Delta p m k 1$, respectively were sensitive to diamide but not to $\mathrm{H}_{2} \mathrm{O}_{2}$ and menadione (Navarro-Garcia et al., 2005; Madrid et al., 2006).

\section{Sensitivity of different Fusarium species to hydrogen peroxide}

We compared the hydrogen peroxide sensitivity of three Fusarium species, F. graminearum PH-1/NRRL 31084, F. oxysporum 4287 and F. verticillioides FGSC 7600 with available genome sequences (http://www.broadinstitute.org/annotation/genome/Fusariumgroup/ Multi Home.html). F. gaminearum, a causal agent of head blight of wheat and stalk/cob rot of maize was the most sensitive to this oxidative stressor both in a decimal conidium dilution assay (Valiante et al., 2007) and in radial growth test (Ádám et al., 2008a). Mycelial growth and conidial germination of this fungus was more strongly inhibited by $5-50 \mathrm{mM}$ and $2 \mathrm{mM}$ $\mathrm{H}_{2} \mathrm{O}_{2}$ concentrations as compared to F. oxysporum and F. verticillioides (Fig 4A, 4B), other two plant pathogenic species causing vascular wilt of a wide range of plants and maize cob rot, respectively. In a previous study (Nicolaou et al., 2009), oxidative stress tolerance of 18 fungal species originating from different ecological niches and phylogenetic positions were compared and plant pathogenic species, like Ustilago maydis, F. graminearum and M. grisea were found to be relatively sensitive to oxidative stressors, including hydrogen peroxide. This result was somewhat surprising as both plant and animal pathogens that are exposed to massive oxidative and/or nitrosative stress by the host cells in many host-pathogen interactions (Brown et al., 2009) would have been expected to acquire improved levels of oxidative stress tolerance during their evolution. When the hydrogen peroxide sensitivity tests were extended to other two Fusarium species, F. fujikuroi MP-C and F. proliferatum FGSC 2287, causing the bakane disease of rice and crown and root rot of a wide range of plants, respectively they also showed higher levels of hydrogen peroxide tolerance as compared to that of $F$. graminearum. The increased $\mathrm{H}_{2} \mathrm{O}_{2}$ sensitivity of $F$. graminearum can be putatively explained by the long saprophytic phase in the life cycle of this species. During the saprophytic phase, F. graminearum lives and propagates on dead tissues and in this niche, the fungus is much less exposed to oxidative stress influence than the other species, that spend much of their life cycle inside living plant tissues either as endophytes or vascular colonizers. 


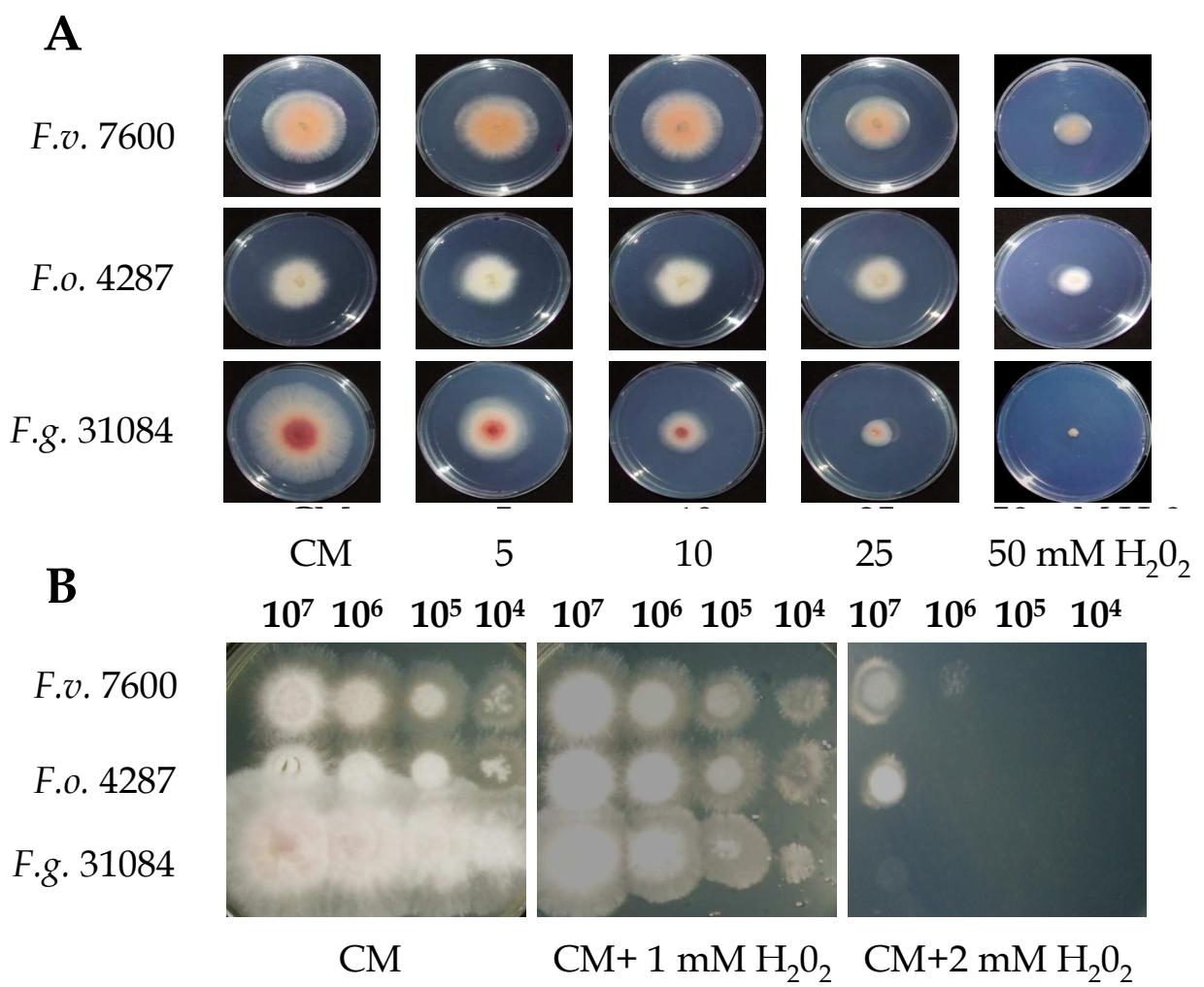

Fig. 4. Growth sensitivity of three Fusarium species: Fusarium verticillioides FGSC 7600, Fusarium oxysporum 4287 and Fusarium graminearum PH-1/NRRL 31084 against hydrogen peroxide $\left(\mathrm{H}_{2} \mathrm{O}_{2}\right)$ in radial growth test $(\mathrm{A})$ and decimal conidial dilution assay (B). In (B) fivefive $\mu$ l of indicated concentrations of conidia (cells $/ \mathrm{ml}$ ) was spotted on complex medium $(\mathrm{CM})$ agar plate and $\mathrm{CM}$ agar plates supplemented with the indicated concentrations of hydrogen peroxide $\left(\mathrm{H}_{2} \mathrm{O}_{2}\right)$. Incubation time was 5 days for plates in (A) and 3 days for plates in (B) at $24^{\circ} \mathrm{C}$.

In another approach we have studied the role of cAMP signaling in oxidative stress response of different Fusarium species. Previous studies in N. crassa demonstrated that cAMP signaling and HOG1 MAPK signaling play opposite role in respect to oxidative stress response: disturbances in the cAMP and the HOG1 pathways result in increased and decreased $\mathrm{H}_{2} \mathrm{O}_{2}$ tolerance, respectively. In F. proliferatum and $F$. verticillioides, disruption of Acy1, the adenylyl cyclase gene resulted in enhanced resistance to heat shock and oxidative stress (Kohut et al., 2010; Choi and $\mathrm{Xu}, 2010$ ). However, in contrast to these data, the acyAmutants of $F$. fujikuroi MP-C were more sensitive to $\mathrm{H}_{2} \mathrm{O}_{2}$ than the wild type (GarcíaMartínez et al., 2011). This finding suggests the high versatility of the cAMP signaling route even in closely related fungi. These differences are particularly important, if we consider that heat shock and oxidative stress pathways have at least partially overlapping signaling routes and regulated by the same transcription factors in yeast (Ikner and Shiozaki, 2005). 


\section{Conclusion}

Functional analysis of orthologous signal transduction genes in different filamentous fungal species highlighted the complex nature of stress signal transduction. This is especially true for oxidative stress signaling, where all fungal MAPK cascades, the HOG1, CWI and PMK MAPK pathways participate and interact in this regulatory network depending on the fungal species. One of the oxidative agents, mehylglyoxal, a toxic by-product of glycolysis is signaled either by the HOG1 MAPK or CWI MAPK pathway in F. verticillioides. All these MAPK cascades are also involved either in positive or negative regulation of secondary metabolite production including mycotoxins in different Fusarium species. The high versatility of oxidative stress and secondary metabolite signaling by the above-mentioned MAPK pathways and the cAMP-PKA pathway in different Fusarium species denotes that stress signaling is exposed to rapid evolution to tune stress responses in a niche-specific manner, independently of the phylogenetic position of a given species.

\section{Acknowledgement}

This research was supported by an OTKA grant (National Scientific Research Council of Hungary, K 76067). We are indebted for support from the Office for Subsidized Research Units of the Hungarian Academy of Sciences. A.L.Á. is also grateful to the HungarianSpanish Bilateral Inter-Governmental S \& T Project (OMFB 00666/2009).

\section{References}

Ádám, A.L., García-Martínez, J., Szŭcs, E.P., Avalos, J., \& Hornok, L. (2011). The MAT1-2-1 mating type gene upregulates photo-inducible carotenoid biosynthesis in Fusarium verticillioides. FEMS Microbiology Letters 318: 76-83.

Ádám, A.L., Kohut, G. \& Hornok, L. (2008a). Fphog1, a HOG-type MAP kinase, is involved in multistress response in Fusarium proliferatum. Journal of Basic Microbiology 48: 151159.

Ádám, A.L., Kohut, G. \& Hornok, L. (2008b). Cloning and characterization of a HOG-type MAP kinase encoding gene from Fusarium proliferatum. Acta Phytopathologica et Entomologica Hungarica 43: 1-13.

Aguilera, J., Rodríguez-Vargas, S. \& Prieto, J. A. (2005). The HOG MAP kinase pathway is required for the induction of methylglyoxal-responsive genes and determines methylglyoxal resistance in Saccharomyces cerevisiae. Molecular Microbiology 56: 228239.

Aguirre, J., Hansberg, W. \& Navarro, R. (2006). Fungal responses to reactive oxygen species. Medical Mycology S44: (Suppl. 1), 101-107.

Brábek, J. \& Hanks, S.K. (2004). Assaying protein kinase activity. In: Signal Transduction Protocols, Methods in Molecular Biology, R.C. Dickson, M.D. Mendenhall (Eds.), Vol. 284, 79-90, Humana Press, DOI: 10.1385/1-59259-816-1:079, Totowa, New York, USA

Brown, A.J.P., Haynes, K. \& Quinn, J. (2009). Nitrosative and oxidative stress responses in fungal pathogenicity. Current Opinion in Microbiology 12: 384-391.

Catlett, N.L., Yoder, O.C \& Turgeon, B.G. (2003). Whole-genome analysis of two-component signal transduction genes in fungal pathogens. Eukaryotic Cell 2: 1151-1161. 
Choi, Y.E. \& Xu, J.R. (2010). The cAMP signaling pathway in Fusarium verticillioides is important for conidiation, plant infection, and stress responses but not fumonisin production. Molecular Plant-Microbe Interactions 23: 522-533.

Di Pietro, A., Garcia-Maceira, F. I., Meglecz, E., \& Roncero, M. I. (2001). A MAP kinase of the vascular wilt fungus Fusarium oxysporum is essential for root penetration and pathogenesis. Molecular Microbiology 39: 1140-1152.

Du, C., Sarfati, J., Latgé, J.P. \& Calderone, R. (2006). The role of the sakA (Hog1) and tcsB $(\sin 1)$ genes in the oxidant adaptation of Aspergillus fumigatus. Medical Mycology 44: 211-218.

García-Martínez, J., Ádám, A.L. \& Avalos, J. (2011). Adenylyl cyclase plays a regulatory role in development, stress and secondary metabolism in Fusarium fujikuroi. 26th Fungal Genetics Conference at Asilomar, Fungal Genetics Reports, S58, p. 205, ISBN 19414765, Asilomar, California, USA, March, 15-20, 2011

Hagiwara, D., Asano, Y., Marui, J., Yoshimi, A., Mizuno, T. \& Abe, K. (2009). Transcriptional profiling of Aspergillus nidulans HogA MAPK signaling pathway in response to fludioxonil and osmotic stress. Fungal Genetics and Biology 46: 868-878.

Hanks, S.K. \& Hunter, T. (1995). Protein kinases 6. The eukaryotic protein kinase superfamily: kinase (catalytic) domain structure and classification. FASEB Journal 8: 576-596.

Hou, Z., Xue, C., Peng, Y., Katan, T., Kistler, H. C. \& Xu, J.R. (2002): A mitogen-activated protein kinase gene (MGV1) in Fusarium graminearum is required for female fertility, heterokaryon formation, and plant infection. Molecular Plant-Microbe Interactions 15: 1119-1127.

Hunter, T. \& Plowman, G. (1997). The protein kinases of budding yeast: six score and more. Trends in Biochemical Sciences 22: 18-22.

Ikner, A. \& Shiozaki, K. (2005). Yeast signaling pathways in the oxidative stress response. Mutation Research/Fundamental and Molecular Mechanisms of Mutagenesis 6: 13-27.

Izumitsu, K., Yoshimi, A., Kubo, D., Morita, A., Saitoh, Y. \& Tanaka, C. (2009). The MAPKK kinase ChSte11 regulates sexual/asexual development, melanization, pathogenicity, and adaptation to oxidative stress in Cochliobolus heterostrophus. Current Genetics 55: 439-448.

Jenczmionka, N. J, Maier, F. J., Lösch, A.P. \& Schäfer, W. (2003). Mating, conidiation and pathogenicity of Fusarium graminearum, the main causal agent of the head-blight disease of wheat, are regulated by the MAP kinase Gpmk1. Current Genetics 43: 8795.

Jenczmionka, N.J. \& Schäfer, W. (2005). The Gpmk1 kinase of Fusarium graminearum regulates the induction of specific secreted enzymes. Current Genetics 47: 29-36.

Kohut, G., Ádám, A.L., Fazekas, B. \& Hornok, L. (2009). N-starvation stress induced FUM gene expression and fumonisin production is mediated via the HOG-type MAPK pathway in Fusarium proliferatum. International Journal of Food Microbiology 130: 6569.

Kohut, G., Oláh, B., Ádám, A.L., García-Martínez, J. \& Hornok, L. (2010). Adenylyl cyclase regulates heavy metal sensitivity, bikaverin production and plant tissue colonization in Fusarium proliferatum. Journal of Basic Microbiology 50: 59-71. 
Krasley, E., Cooper, K.F., Mallory, M.J., Dunbrack, R. \& Strich, R. (2006). Regulation of the oxidative stress response through Slt2p-dependent destruction of cyclin C in Saccharomyces cerevisiae. Genetics 172: 1477-1486.

Liu, W., Leroux, P. \& Fillinger, S. (2008). The Hog1-like MAP kinase Sak1 of Botrytis cinerea is negatively regulated by the upstream histidine kinase Bos1 and is not involved in dicarboximide and phenylpyrrole resistance. Fungal Genetics and Biology 45: 10621074.

Madrid, M., Soto, T., Khong, H.K., Franco, A., Vicente, J., Pérez, P., Gacto, M., \& Cansado, J. (2006). Stress-induced response, localization, and regulation of the Pmk1 cell integrity pathway in Schizosaccharomyces pombe. Journal of Biological Chemistry 281: 2033-2043.

Manning, G., Whyte, D.B., Martinez, R., Hunter, T. \& Sudarsanam, S. (2002). The protein kinase complement of the human genome. Science 298: 1912-1934.

Motoyama, T.K., Kodama, T., Ohira, A., Ichiishi, M., Fujimura, I., Yamaguchi, I. \& Kubo, T. (2005). A two-component histidine kinase of the rice blast fungus is involved in osmotic stress response and fungicide action. Fungal Genetics and Biology 42: 200212.

Navarro-García, F., Eisman, B., Fiuza, S.M., Nombela, C. \& Pla, J. (2005). The MAP kinase Mkc1p is activated under different stress conditions in Candida albicans. Microbiology 151: 2737-2749.

Nikolaou, E., Agrafioti, I., Stumpf, M., Quinn, J., Stansfield, I. \& Brown, A.J.P. (2009). Phylogenetic diversity of stress signalling pathways in fungi. BMC Evolutionary Biology 9: 44-59.

Noguchi, R., Banno, S., Ichikawa, R., Fukumori, F., Ichiishi, A., Kimura M., Yamaguchi, I. \& Fujimura, M. (2007). Identification of OS-2 MAP kinase-dependent genes induced in response to osmotic stress, antifungal agent fludioxonil and heat shock in Neurospora crassa. Fungal Genetics and Biology 44: 208-18.

Ochiai, N., Fujimura, M., Motoyama, T., Ichiishi, A., Usami, R., Horikoshi, K. \& Yamaguchi, I. (2001). Characterization of mutations in the two-component histidine kinase gene that confer fludioxonil resistance and osmotic sensitivity in the os-1 mutants of Neurospora crassa. Pest Management Science 57: 437-442.

Ochiai, N., Tokai, T., Nishiuchi, T., Takahashi-Ando, N., Fujimura, M. \& Kimura, M. (2007). Involvement of the osmosensor histidine kinase and osmotic stress-activated protein kinases in the regulation of secondary metabolism in Fusarium graminearum. Biochemical Biophysical Resaearch Communications 363: 639-644.

Pócsi, I., Miskei, M., Karányi, Z., Emri, T., Ayoubi, P., Pusztahelyi, T., Balla, G. \& Prade, R.A. (2005). Comparison of gene expression signatures of diamide, $\mathrm{H}_{2} \mathrm{O}_{2}$ and menadione exposed Aspergillus nidulans cultures - linking genome-wide transcriptional changes to cellular physiology. BMC Genomics 6: 182-201.

Rispail, N. \& Di Pietro, A. (2010). The two-component histidine kinase Fhk1 controls stress adaptation and virulence of Fusarium oxysporum. Molecular Plant Pathology 11: 395407.

Rispail, N., Soanes, D.M. \& Di Pietro, A. (2009). Comparative genomics of MAP kinase and calcium calcineurin signalling components in plant and human pathogenic fungi. Fungal Genetics and Biology 46: 287-298. 
Thön, M., Al-Abdallah, Q., Hortschansky, P. \& Brakhage, A.A. (2007). The thioredoxin system of the filamentous fungus Aspergillus nidulans: impact on development and oxidative stress response. Journal of Biologycal Chemistry 282: 27259-27269.

Torres-Quiroz, F., García-Marqués, S., Coria, R., Randez-Gil, F. \& Prieto, J.A. (2010). The activity of yeast Hog1 MAPK is required during endoplasmic reticulum stress induced by tunicamycin exposure. Journal of Biological Chemistry 285: 20088-20096.

Yoshimi, A., Tsuda, M. \& Tanaka, C. (2004). Cloning and characterization of the histidine kinase gene Dic1 from Cochliobolus heterostrophus that confers dicarboximide resistance and osmotic adaptation. Molecular Genetics Genomics 271: 228-236.

Yoshimi, A., Kojima, K., Takano, Y. \& Tanaka, C. (2005). Group III histidine kinase is a positive regulator of Hog1-type mitogen-activated protein kinase in filamentous fungi. Eukaryotic Cell 4: 1820-1828.

Valiante, V., Heinekamp, T., Jain, R., Härtl, A. \& Brakhage, A.A. (2007). The mitogenactivated protein kinase MpkA of Aspergillus fumigatus regulates cell wall signaling and oxidative stress response. Fungal Genetics and Biology 45: 618-627.

Viaud, M., Fillinger, S., Liu, W., Polepalli, J.S., Le Pêcheur, P., Kunduru, A.R., Leroux, P. \& Legendre, L. (2006). A class III histidine kinase acts as a novel virulence factor in Botrytis cinerea. Molecular Plant-Microbe Interactions 19: 1042-1050.

Zhang, Y., Choi, Y.E., Zou, X. \& Xu, J.R. (2011). The FvMK1 mitogen-activated protein kinase gene regulates conidiation, pathogenesis, and fumonisin production in Fusarium verticillioides. Fungal Genetics and Biology 48: 71-9.

Zhang, Y. , Lamm, R. , Pillonel, C., Lam, S. \& Xu, J.R. (2002). Osmoregulation and fungicide resistance: the Neurospora crassa os-2 gene encodes a HOG1 mitogen-activated protein kinase homologue. Applied and Environmental Microbiology 68: 532-538. 


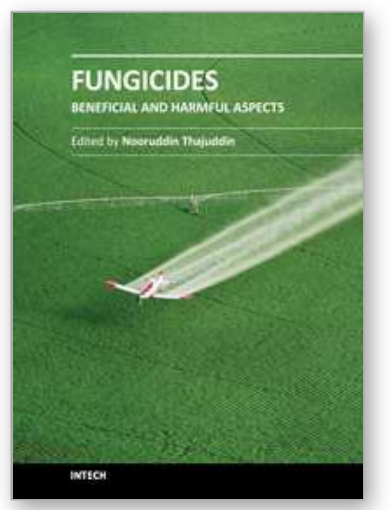

\author{
Fungicides - Beneficial and Harmful Aspects \\ Edited by Dr. Nooruddin Thajuddin
}

ISBN 978-953-307-451-1

Hard cover, 254 pages

Publisher InTech

Published online 16, December, 2011

Published in print edition December, 2011

Fungicides are a class of pesticides used for killing or inhibiting the growth of fungus. They are extensively used in pharmaceutical industry, agriculture, in protection of seed during storage and in preventing the growth of fungi that produce toxins. Hence, fungicides production is constantly increasing as a result of their great importance to agriculture. Some fungicides affect humans and beneficial microorganisms including insects, birds and fish thus public concern about their effects is increasing day by day. In order to enrich the knowledge on beneficial and adverse effects of fungicides this book encompasses various aspects of the fungicides including fungicide resistance, mode of action, management fungal pathogens and defense mechanisms, ill effects of fungicides interfering the endocrine system, combined application of various fungicides and the need of GRAS (generally recognized as safe) fungicides. This volume will be useful source of information on fungicides for post graduate students, researchers, agriculturists, environmentalists and decision makers.

\title{
How to reference
}

In order to correctly reference this scholarly work, feel free to copy and paste the following:

Emese D. Nagygyörgy, László Hornok and Attila L. Adám (2011). Role of MAP Kinase Signaling in Secondary Metabolism and Adaptation to Abiotic/Fungicide Stress in Fusarium, Fungicides - Beneficial and Harmful Aspects, Dr. Nooruddin Thajuddin (Ed.), ISBN: 978-953-307-451-1, InTech, Available from:

http://www.intechopen.com/books/fungicides-beneficial-and-harmful-aspects/role-of-map-kinase-signaling-insecondary-metabolism-and-adaptation-to-abiotic-fungicide-stress-in-f

\section{INTECH}

open science | open minds

\section{InTech Europe}

University Campus STeP Ri

Slavka Krautzeka 83/A

51000 Rijeka, Croatia

Phone: +385 (51) 770447

Fax: +385 (51) 686166

www.intechopen.com

\section{InTech China}

Unit 405, Office Block, Hotel Equatorial Shanghai

No.65, Yan An Road (West), Shanghai, 200040, China

中国上海市延安西路65号上海国际贵都大饭店办公楼405单元

Phone: +86-21-62489820

Fax: $+86-21-62489821$ 
(C) 2011 The Author(s). Licensee IntechOpen. This is an open access article distributed under the terms of the Creative Commons Attribution 3.0 License, which permits unrestricted use, distribution, and reproduction in any medium, provided the original work is properly cited. 